\title{
Implementing a sustainable health insurance system in Cambodia: a study protocol for developing and validating an efficient household income-level assessment model for equitable premium collection
}

Haruyo Nakamura ${ }^{1 *}$ D, Floriano Amimo ${ }^{1,2}$, Siyan $\mathrm{Yi}^{3,4,5}$, Sovannary Tuot ${ }^{3}$, Tomoya Yoshida ${ }^{6}$, Makoto Tobe ${ }^{6,7}$ and Shuhei Nomura ${ }^{1,8}$

\begin{abstract}
Background: As elsewhere in low- and middle-income countries, due to limited fiscal resources, universal health coverage (UHC) remains a challenge in Cambodia. Since 2016, the National Social Security Fund (NSSF) has implemented a social health insurance scheme with a contributory approach for formal sector workers. However, informal sector workers and dependents of formal sector workers are still not covered by this insurance because it is difficult to set an optimal amount of contribution for such individuals as their income levels are inestimable. The present study aims to develop and validate an efficient household income-level assessment model for Cambodia. We aim to help the country implement a financially sustainable social health insurance system in which the insured can pay contributions according to their ability.

Methods: This study will use nationally representative data collected by the Cambodia Socio-Economic Survey (CSES), covering the period from 2009 to 2019, and involving a total of 50,016 households. We will employ elastic net regression analysis, with per capita disposable income based on purchasing power parity as the dependent variable, and individual and community-level socioeconomic and demographic characteristics as independent variables. These analyses aim to create efficient income-level assessment models for health insurance contribution estimation. To fully capture socioeconomic heterogeneity, sub-group analyses will be conducted to develop separate income-level assessment models for urban and rural areas, as well as for each province.
\end{abstract}

Discussion: This research will help Cambodia implement a sustainable social health insurance system by collecting optimal amount of contributions from each socioeconomic group of the society. Incorporation of this approach into existing NSSF schemes will enhance the country's current efforts to prevent impoverishing health expenditure and to achieve UHC.

Keywords: Health financing, Financial sustainability, Health insurance, Contribution, Income-level assessment, Equity, Cambodia

\footnotetext{
* Correspondence: hnakamura@m.u-tokyo.ac.jp

${ }^{1}$ Department of Global Health Policy, Graduate School of Medicine, The

University of Tokyo, 7-3-1 Hongo, Bunkyo-ku, Tokyo 113-0033, Japan

Full list of author information is available at the end of the article
}

(c) The Author(s). 2020 Open Access This article is distributed under the terms of the Creative Commons Attribution 4.0 International License (http://creativecommons.org/licenses/by/4.0/), which permits unrestricted use, distribution, and reproduction in any medium, provided you give appropriate credit to the original author(s) and the source, provide a link to the Creative Commons license, and indicate if changes were made. The Creative Commons Public Domain Dedication waiver (http://creativecommons.org/publicdomain/zero/1.0/) applies to the data made available in this article, unless otherwise stated. 


\section{Background}

Globally, approximately 180 million individuals are estimated to be facing catastrophic health expenditure each year [1]. Therefore, at the General Assembly held in December 2012, the United Nations set the achievement of universal health coverage (UHC) as a new common agenda for the global community [2]. Nevertheless, for low- and middle-income countries (LMICs), it is financially challenging to establish a publicly funded system to achieve UHC targets due to insufficient tax revenue. Accordingly, some LMICs have chosen to adopt a contributory health insurance system to effectively mobilize domestic financing resources [3].

A contributory health insurance is typically introduced for the population employed in the formal sector, such as civil servants and private sector workers, since insurance contributions can be deducted from their salaries. Meanwhile, most LMICs simultaneously provide social and health assistance to poor individuals, often in collaboration with development partners. As a result, nonpoor informal sector workers and dependents of formal sector workers are left uninsured [3]. Countries that adopt a contributory health insurance system to cover the general population usually collect a fixed amount of contribution, which is set at a level that the lowestincome group can afford. Such a practice, however, endangers the financial sustainability of the insurance fund or imposes heavy burden of subsidy on the government, whose fiscal resources are already limited [3]. Therefore, there is an urgent need to develop a mechanism to assess household income level to collect contributions according to one's ability to pay, while ensuring financial sustainability of the insurance fund and placing minimum burden on the governments of LMICs.

Since 2016, in Cambodia, a lower-middle-income country [4], the National Social Security Fund (NSSF) has provided health insurance coverage to formal sector workers. In contrast, poor households are covered by the Health Equity Fund (HEF), the co-financing mechanism of the government and development partners. The government plans to extend the NSSF health insurance system to the rest of the population by 2025 [5]. In December 2017, approximately 31\% of Cambodian citizens were covered either by the NSSF health insurance or HEF [6]. Thus, nearly $70 \%$ of the population is yet to be covered by health insurance.

The National Institute of Statistics (NIS) under the Ministry of Planning of Cambodia conducts the Cambodia Socio-Economic Survey (CSES) each year, to specifically estimate household income in the country, the key information required for equitable contribution estimation [7]. However, this survey is composed of lengthy questionnaires, which require an average of 2 days to complete in each household. Therefore, the
CSES questionnaires are unlikely to be utilized regularly by local administrative staff to estimate health insurance contribution. A more efficient tool with limited number of indices to allow an easy, quick, but accurate assessment of the household income level is therefore needed in Cambodia. By identifying the income level of households efficiently, the emerging insurance model could allow the redistribution of wealth because larger contributions could be collected from individuals with higher income as compared to that collected from those with lower income, while simultaneously ensuring equity in access to health care. Studies conducted in Egypt [8], India [9, 10], and Iran [11] have attempted to develop socioeconomic or economic status measurement questionnaires and/or to improve existing ones for health research and welfare assessments. These attempts found the possibility of estimating the socioeconomic status of each household and individual using a limited number of indices. In Cambodia, poor households are identified using the proxy means test [12]. However, no study has so far focused on measuring the household income level applicable to health insurance contribution estimation.

Accordingly, the present study aims to develop and validate an efficient household income-level assessment model for Cambodia by using only selected independent variables and respective regression coefficients. The final product of the study will be an automated tool that predicts the income level of a household, which will further determine the optimal amount of health insurance contribution for each household. If the model determines that subnational administrative location is relevant for predicting income, it will be included in the tool, thus rendering the model useful for nationwide application. This will help the country implement a financially sustainable social health insurance system in which the insured can pay contributions according to their ability.

\section{Methods \\ Data source}

This study will use the CSES 2009-2019 data [7, 13-20], provided by the NIS, that is publicly accessible on request. These data contain demographic characteristics; housing conditions; and household-level production, income, consumption, and ownership of assets. The CSES is a nationally representative cluster sample survey using systematic sampling with probabilities proportional to the size of the stratum. The sample sizes for urban and rural areas are calculated using the proportion of consumption in the two parts of the population with the preceding CSES data. The interview was conducted for the head of the household, his/her spouse, or any other adult household member if the head and spouse were absent. The NIS conducts the survey annually, and it covered 12,000 households in 2009, 3600 in 
2010-2013, 12,096 in 2014, and 3840 in 2015-2017. The CSES was not conducted in 2018 as the NIS was revising the questionnaires. Although the details regarding CSES 2019 have not been published, we expect to include the CSES 2019 data in our analyses based on the timeline for data availability from the NIS.

For this study, we plan to use data from the 50,016 households covered in the CSES 2009-2017, plus those from CSES 2019. We will use pooled cross-sectional data from several years to utilize a larger sample size that would increase precision and power, and allow assessment of the effect year in the estimation of income.

To define income composition and distribution for households, the CSES uses the Recommendations on Household Income Statistics by the Canberra Expert Group [7]. The CSES estimates household income by asking over 60 questions regarding revenue and costs of each economic activity, including those related to agriculture, non-agriculture, and owner-occupied houses, and other types of income and transfers. Since there is no bookkeeping in households, one has to rely on data from interviews on both revenue and costs for the households as business. The CSES's estimation is based on the recall and diary data on the items listed in Table 1.

\section{Analyses}

The data will be divided into a training set and a validation set using the 9:1 ratio randomly. This training-and

Table 1 Composition of household income

\begin{tabular}{ll}
\hline 1. Primary income & \\
\hline 1.1 & Salary \\
\hline 1.3 & Agricultural income \\
1.4 & Non-agricultural income \\
1.5 & Income from owner's house occupied \\
2. Total transfers & Income from property \\
2.1 & \\
2.2 & Total private transfers \\
2.3 & Scholarship \\
2.4 & Gifts \\
2.5 & Other transfers \\
2.6 & NGO transfers \\
3. Total income (1+2) & Pension \\
4. Negative transfers & \\
4.1 & \\
4.2 & Taxes \\
4.3 & Inter-household transfers \\
5. Disposable income (3- 4) & Cash transfers to charities \\
\hline
\end{tabular}

Source: Cambodia Socio-Economic Survey 2014 [7] validation-set size ratio was determined to optimize the trade-off between the complexity of the first and second levels of inference [21]. Subsequently, the analyses will be conducted in two steps.

In the first step, using the training set, we will perform elastic net regression with per capita disposable income based on purchasing power parity as the dependent variable and the socioeconomic factors listed in Table 2 as independent variables. Here, we will use the variables discussed in similar studies to create our pool of independent variables. Household size could be an independent variable as it affects per capita household income, while it is also used for computing the average income of each household member. Then we will apply elastic net regression to identify variables that are most relevant for predicting income given the context [8-11]. Elastic net regression is a widely applied technique that performs data-driven automatic variable selection and regularization to optimize predictive performance on future data while ensuring model parsimony [22, 23]. Per capita disposable income in international dollars will be derived from per capita disposable monthly income in the local currency, using a purchasing power parity conversion factor from the World Bank [24]. This will ensure the international comparability and validity of the findings over time within the country, given the volatility of the local currency and prices. To account for the variance in the estimation of per capita disposable income based on purchasing power parity, the household size used to estimate per capita disposable income in each household will be used to construct analytic weights for the modelling framework. K-fold cross-validation will be used to select the optimal alpha and lambda hyperparameters for the model. Additionally, we will conduct subgroup analyses, which will allow us to develop separate income-level assessment models for each socioeconomic group of the society, including the urban and rural areas, administrative regions, and sectors of economic activity, taking their socioeconomic heterogeneity into account.

In the second step, the trained model will be validated using the validation data subset. Using this subset, we will predict the income level of each household and further classify the households into income quintile groups. The results will also be compared with the income quintiles reported by the CSES, which used the full-length income-assessment questionnaires. The same data subset of the CSES 2009-2019 will be utilized using the F-score, which represents the harmonic mean of the positive predictive value and true positive rate [23]. By using large data, we have made the ratio of training- and validation- datasets larger than usual, at 9:1, as 5000 observations are large enough for validation. Finally, we will conduct sensitivity analyses to explore the effect of using different training- and validation-set size ratios on 
Table $\mathbf{2}$ List of variables tested in the development of the income assessment framework

\section{Dependent variable}

- Disposable per capita income

Independent variables

Demographic characteristics

- Household size

- Whether there is no male/female in a household

- Sex, age and ethnicity of the household head

- Whether the household head has a spouse

- Number of household members who received college-level or higher education

- Number of household members who received high-school-level or higher education

- Number of literate household members

- Number of household members who currently go to private school

- Number of household members who are currently receiving private lessons

- Total payment for household members' education in the past year

- Number of household members who speak French/English/Chinese Geographic characteristics

- Urban or Rural (Primary Sampling Unit basis) residence

- Provincial/district/commune/village code

Housing

- Materials used for the dwelling roof/wall/floor

- Source of light/drinking water

- Type of toilet facility/cooking fuel

- Whether/how the household treated drinking water in the past month

-Water/sewage/garbage/electricity/gas bill

Property

- The number/price of the household's buildings

- Whether the household rents out buildings

- Rent value of the household's buildings

- Whether the household renovated buildings

- Number of households sharing the dwelling

- Area size of the dwelling

- Number of rooms in the dwelling

- Rent that the household paid in the past month

- Amount that the household paid for maintenance of the own buildings

- Whether the household owns the dwelling

- Whether the household owns or operates a pond

- Number of ponds the household owns

- Total area size/price/monthly rent value of the household's ponds

- Number of land plots that the household owns or operats

- Total area size/total value of the household's lands

- Whether the household owned or operated land for farming in the
Table $\mathbf{2}$ List of variables tested in the development of the income assessment framework (Continued)

past year

- Number of wet-season/dry-season land plots that the household owns

- Number of land plots that the household grows rice/non-rice crops/permanent crops

- Whether the household can add water to land in the wet/dry season

Liability

- Whether the household has an outstanding loan

- Number/total amount of the household's outstanding loans

- Whether the household sold land in the past year

Livestock

- Whether a household member raised livestock in the past year

- Number/value of cattle/buffaloes/pigs/chicken/duck/ that the household has

- Whether a household member raised/caught fish in the past year Economic Activities

- Number of income-earners in the household

- Total number of household members working in foreign countries

- Whether a household member grew/stored/sold crops in the last season

- Total crops that the household produced in the last season

- Whether a household member ran a business or enterprise in the past year

- Total household members employed by the government/ enterprise/household sector/aid organization, etc.

- Total household members who are employers/employees/selfemployed, etc

- Total household members who are technicians/professionals/ managers/service and sales workers/skilled agricultural workers/craft workers/plant operators/technicians, etc.

Durable Goods

- Whether the household has an AC/ bed/ bicycle/ bulldozer/ cabinet/ camera/ car/ cart/ cell phone/ computer/ dining set/ dish washer/ electric fan/ electronic iron/ freezer/ gas kitchen/ generator/ hand tractor/ harrow/ motorcycle/ motor boat/ music instrument/ phone/ plough/ printer/ pump/ radio/ refrigerator/ rice mill/ rowing boat/ satellite/ sewing machine/ sofa set/ sport good/ stereo/ threshing machine/ tractor/ TV/ vacuum/ video/washing machine

- Number of the above durable goods that the household owns

Source: Cambodia Socio-economic Survey 2009-2017 [7, 13-20]

our inferences. All analyses will be conducted in Stata 15.0 and R 3.5.1. A $P$ value $<0.05$ will be considered statistically significant.

\section{Discussion}

This research will help Cambodia implement a sustainable social health insurance system by collecting an optimal amount of contribution from each socioeconomic group of the society. For the first time, our approach will 
Table 3 Projected fixed and equitable contributions per capita by quintile groups in Cambodia, 2019

\begin{tabular}{|c|c|c|c|c|c|c|}
\hline & \multirow[b]{2}{*}{$\begin{array}{l}\text { Projected } \\
\text { income (USD) }\end{array}$} & \multirow[b]{2}{*}{$\begin{array}{l}\text { Projected income } \\
\text { distribution }\end{array}$} & \multicolumn{2}{|l|}{ Fixed contribution } & \multicolumn{2}{|c|}{ Equitable contribution } \\
\hline & & & $\begin{array}{l}\text { Projected } \\
\text { contribution (USD) }\end{array}$ & $\begin{array}{l}\text { Projected contribution } \\
\text { share in income }\end{array}$ & $\begin{array}{l}\text { Projected } \\
\text { contribution (USD) }\end{array}$ & $\begin{array}{l}\text { Projected contribution } \\
\text { share in income }\end{array}$ \\
\hline I & 19.0 & $2.6 \%$ & 3.3 & $17.3 \%$ & 0.4 & $2.2 \%$ \\
\hline$\|$ & 76.0 & $10.4 \%$ & 3.3 & $4.3 \%$ & 1.7 & $2.2 \%$ \\
\hline III & 116.8 & $16.0 \%$ & 3.3 & $2.8 \%$ & 2.6 & $2.2 \%$ \\
\hline IV & 166.9 & $22.8 \%$ & 3.3 & $2.0 \%$ & 3.8 & $2.2 \%$ \\
\hline V & 352.0 & $48.2 \%$ & 3.3 & $0.9 \%$ & 7.9 & $2.2 \%$ \\
\hline
\end{tabular}

Note: 1 USD $=4050.58$ Cambodian Riels [25]. Quintile I and V are the lowest and highest income groups, respectively. Source: Japan International Cooperation Agency [26]

allow for an equitable contribution collection from all the households by determining a pool of a few highly predictive indices that can reliably provide an accurate estimation of per capita income, while ensuring feasibility of the insurance fund by allowing informed planning with accurate estimation of the revenue pool. Incorporation of our proposed insurance framework into the existing NSSF schemes will thus enhance the country's current efforts to prevent impoverishing health expenditure and to achieve UHC targets. Our results will be compared with the fixed health insurance contribution estimated in a previous study based on medical benefit costs, administration costs, and capital buffer added, as illustrated in Table 3 [26]. Furthermore, applicability of the income-assessment tool will be tested in a subsequent pilot study.

Despite our innovative methodology to estimate income, there are some practical difficulties that would need to be addressed in the field to collect these contributions. These include unwillingness to make payments, particularly for an unfamiliar expense such as health insurance. Even if individuals pay their contributions, embezzlement could be a problem. Additionally, it might be costly to collect contributions. Therefore, additional efforts from the Government of Cambodia might be required for the successful implementation of our approach. Actions could include legislating compulsory health insurance contributions, setting up a mechanism of peer pressure in the contribution collection, using electronic money transfer methods, including automatic withdrawal from bank account, as well as utilizing the existing local administrative system to collect contributions. Furthermore, though the present study will not use self-reported income as this will be predicted using non-income data, there is still the issue of social desirability and recall bias which constitute the limitations of the study.

\section{Abbreviations}

CSES: Cambodia socio-economic survey; LMICs: Low- and middle-income countries; NIS: National institute of statistics; NSSF: National social security fund; UHC: Universal health coverage
Acknowledgements

Not applicable.

\section{Authors' contributions}

HN conceived of and designed the study, drafted the protocol, and acquired the data. HN will analyze the data, interpret and discuss the results, and draft the final manuscript. FA designed the statistical framework and will support data analysis. SY and ST confirmed the quality of the data and study design considering local contexts and previous studies in the field. TY and MT confirmed the quality and availability of data, and ensured that any part of the work that is related to the Japan International Cooperation Agency's project is accurately and appropriately described. SN is responsible for the integrity of the data and the accuracy of the data analyses, and will oversee the study. All the authors made critical revisions to the manuscript for important intellectual content, approved the final version of the manuscript, and will support the interpretation and discussion of findings.

\section{Funding}

Not applicable.

\section{Availability of data and materials}

The datasets that support the findings of this study are available from the National Institute of Statistics (NIS), Ministry of Planning of Cambodia. Data are available upon reasonable request and with permission of the NIS.

Ethics approval and consent to participate

Not applicable. Ethical approval is not required because the study will use data, documents, and records that are publicly accessible, and all individual data are non-identifiable.

\section{Consent for publication}

Not applicable.

\section{Competing interests}

The authors declare that they have no competing interests.

\section{Author details}

${ }^{1}$ Department of Global Health Policy, Graduate School of Medicine, The University of Tokyo, 7-3-1 Hongo, Bunkyo-ku, Tokyo 113-0033, Japan. ${ }^{2}$ Faculty of Medicine, Eduardo Mondlane University, Maputo, Mozambique. ${ }^{3}$ KHANA Center for Population Health Research, Phnom Penh, Cambodia. ${ }^{4}$ Center for Global Health Research, Touro University California, Vallejo, CA, USA. ${ }^{5}$ Saw Swee Hock School of Public Health, National University of Singapore and National University Health System, Singapore, Singapore. ${ }^{6} J a p a n$ International Cooperation Agency, Tokyo, Japan. ${ }^{7}$ Research Center for Health Policy and Economics, Hitotsubashi Institute for Advanced Study, Hitotsubashi University, Tokyo, Japan. ${ }^{8}$ Department of Health Policy and Management, School of Medicine, Keio University, Tokyo, Japan. 
Received: 9 October 2019 Accepted: 9 January 2020

Published online: 31 January 2020

\section{References}

1. World Health Organization. Catastrophic out-of-pocket health spending (SDG indicator 3.8.2) Estimates by WHO region in Global Health Observatory data repository. 2010. http://apps.who.int/gho/data/view.main. FINANCIALPROTECTIONWHOREG01v?lang=en. Accessed 10 May 2019.

2. Universal Health Coverage Coalition. UN Resolution 2012. http://healthforall. org/un-resolution/. Accessed 3 May 2019.

3. Maeda A, Araujo E, Cashin C, Harris J, Ikegami N, Reich R. Universal health coverage for inclusive and sustainable development a synthesis of 11 country case studies. Washington DC: The World Bank; 2014.

4. The World Bank. World Bank country and lending groups. 2019. https:// datahelpdesk.worldbank.org/knowledgebase/articles/906519-world-bankcountry-and-lending-groups. Accessed 2 Jun 2019.

5. The Royal Government of Cambodia. National Social Protection Policy Framework 2016-2025. Phnom Penh: The Council of Ministers; 2017

6. National Social Security Fund. Achievements over the period of 10 years (2008-2017) and Direction for 2018. Presented by H.E. Ouk Samvithjea, Delegate of the Royal Government in charge of National Social Security Fund. Phnom Penh Hotel, 6 March 2018.

7. National Institute of Statistics, Ministry of Planning, the Kingdom of Cambodia. Cambodia Socio-Economic Survey 2014. 2015. http://www. nis.gov.kh/nis/CSES/Final\%20Report\%20CSES\%202014.pdf. Accessed 3 Feb 2019.

8. El-Gilany A, El-Wehady A, El-Wasify M. Updating and validation of the socioeconomic status scale for health research in Egypt. Eastern Mediterr Health J. 2012:18(9):962-8.

9. Gaur KL. Socio-economic status measurement scale: thirst area with changing concept for socio-economic status. Int J Innov Res and Dev. 2013; 2(9):139-45.

10. Singh T, Sharma S, Nagesh S. Socio-economic status scales updated for 2017. Int J Res Med Sci. 2017;5(7):3264-7.

11. Tajik P, Majdzadeh R. Constructing pragmatic socioeconomic status assessment tools to address health equality challenges. Int J Prev Med. 2014:5(1):46-51.

12. Ministry of Planning, the Kingdom of Cambodia. Identification of poor households programme IDPOOR information system. 2015. http://www. idpoor.gov.kh/en/home. Accessed 16 Jul 2019

13. National Institute of Statistics, Ministry of Planning, the Kingdom of Cambodia. Cambodia Socio-Economic Survey 2009. 2010. http://www. nis.gov.kh/nis/CSES/Final\%20Report\%20CSES\%202009.pdf. Accessed 3 Feb 2019.

14. National Institute of Statistics, Ministry of Planning, the Kingdom of Cambodia. Cambodia Socio-Economic Survey 2010. 2011. http://www. nis.gov.kh/nis/CSES/Final\%20Report\%20CSES\%202010.pdf. Accessed 3 Feb 2019.

15. National Institute of Statistics, Ministry of Planning, the Kingdom of Cambodia. Cambodia Socio-Economic Survey 2011. 2012. http://ghdx. healthdata.org/record/cambodia-socio-economic-survey-2011. Accessed 3 Feb 2019.

16. National Institute of Statistics, Ministry of Planning, the Kingdom of Cambodia. Cambodia Socio-Economic Survey 2012. 2013. http://www. nis.gov.kh/nis/CSES/Final\%20Report\%20CSES\%202012.pdf. Accessed 3 Feb 2019

17. National Institute of Statistics, Ministry of Planning, the Kingdom of Cambodia. Cambodia Socio-Economic Survey 2013. 2014. http://www. nis.gov.kh/nis/CSES/Final\%20Report\%20CSES\%202013.pdf. Accessed 3 Feb 2019.

18. National Institute of Statistics, Ministry of Planning, the Kingdom of Cambodia. Cambodia Socio-Economic Survey 2015. 2016. http://www. nis.gov.kh/nis/CSES/Final\%20Report\%20CSES\%202015.pdf. Accessed 3 Feb 2019

19. National Institute of Statistics, Ministry of Planning, the Kingdom of Cambodia. Cambodia Socio-Economic Survey 2016. 2017. http://www. nis.gov.kh/nis/CSES/Final\%20Report\%20CSES\%202016.pdf. Accessed 3 Feb 2019.

20. National Institute of Statistics, Ministry of Planning, the Kingdom of Cambodia. Cambodia Socio-Economic Survey 2017. 2018. http://www.
nis.gov.kh/nis/CSES/Final\%20Report\%20CSES\%202017.pdf. Accessed 3 Feb 2019.

21. He Q, Lin DY. A variable selection method for genome-wide association studies. Bioinformatics. 2010;27:1-8.

22. Jarata TN, Rokne J, Alhajj R. Highlighting the importance of big data management and analysis for various applications. New York: Springer International Publishing; 2017.

23. Tharwat A. Classification assessment methods. Appl Comput Inform 2018; https://doi.org/https://doi.org/10.1016/j.aci.2018.08.003.

24. The World Bank. PPP calculation and estimation. 2019. https://www. worldbank.org/en/programs/icp/brief/methodology-calculation. Accessed 13 Dec 2019

25. The World Bank. Official exchange rate (LCU per US\$, period average), International Monetary Fund, International Financial Statistics. 2019. https:// data.worldbank.org/indicator/PA.NUS.FCRF. Accessed 19 Jun 2019.

26. Japan International Cooperation Agency (JICA), Global Link Management Inc., Ministry of Health, The Kingdom of Cambodia. The project for development of social health insurance for the informal sector in the Kingdom of Cambodia: final report. Tokyo: JICA; 2018. https://libopac.jica.go. jp/images/report/12322236.pdf

\section{Publisher's Note}

Springer Nature remains neutral with regard to jurisdictional claims in published maps and institutional affiliations.
Ready to submit your research? Choose BMC and benefit from:

- fast, convenient online submission

- thorough peer review by experienced researchers in your field

- rapid publication on acceptance

- support for research data, including large and complex data types

- gold Open Access which fosters wider collaboration and increased citations

- maximum visibility for your research: over $100 \mathrm{M}$ website views per year

At BMC, research is always in progress.

Learn more biomedcentral.com/submissions 